\title{
Social and Behavioral Sciences Research: is now the time to invest?
}

\author{
Steve Goddard, Associate Vice Chancellor for Research, \\ University of Nebraska-Lincoln \\ Dan Hoyt, Director, Social and Behavioral Sciences Research Consortium, \\ University of Nebraska
}

S ocial and behavioral sciences are broad, interrelated fields of study. The core social sciences consist of anthropology, economics, geography, sociology, and political science. Researchers in the social sciences often use methods similar to the natural sciences as tools for understanding human behavior in societal contexts. The behavioral sciences consist of education, psychology, social neuroscience, communication and cognitive science, and researchers in these fields often use empirical data to investigate the decision processes and communication strategies. Within the structure of universities we also find social and behavioral scientists located across a broad range of academic units including agricultural economics, demography, educational psychology, health and nutrition, and public health. Researchers in both groups frequently engage a combination of basic and applied research, with the applied research typically involving interventions designed to improve health and related outcomes.

The National Science Foundation (NSF) and the National Institutes of Health (NIH) fund the majority of social and behavioral sciences research (SBSR) in the U.S., though agencies such as the Department of Education (DoE), the Department of Defense (DoD), the Department of Agriculture (USDA), the Center for Disease Control and Prevention (CDC), the National Institute of Justice (NIJ) and the Administration for Children and Families. The Agency for Healthcare Research and Quality (AHRQ) are also well known supporters of SBSR. Nationally, SBSR receives $\$ 921 \mathrm{M}$ in federal funding. While significant, this amount pales in comparison to the $\$ 40.1 \mathrm{~B}$ of federal funding for all science and engineering. Typical SBSR grants range in value from $\$ 10 \mathrm{~K}$ to $\$ 7 \mathrm{M}$. The following list of selected active University of Nebraska-Lincoln (UNL) grants illustrates this range:

- Doctoral Dissertation improvement grant (NSF): \$11,997

- Alcohol, Trauma and Intrusions (NIH): \$128,916

- Intelligent Support to Deterrence Operations (DoD): \$99,811

- Redesigning Science Surveys (USDA): \$115,000

- Ecological Model of Latino Youth (NSF): \$339,935

- Randomized Trial in Rural Education (DoE): \$2,999,994

- Native American Substance Abuse Prevention (NIH): \$3,762,799 


\begin{tabular}{|c|c|c|c|}
\hline State & $\begin{array}{l}\text { Total SBSR } \\
\text { Funding }\end{array}$ & Funding by Agency & Top Universities \\
\hline Iowa & \$21.2 Million & $\begin{array}{l}\text { NIH \$11.6 Million } \\
\text { NSF \$ 1.6 Million } \\
\text { Other \$ } 7.6 \text { Million }\end{array}$ & $\begin{array}{ll}\text { U. of Iowa } & \$ 11.1 \mathrm{M} \\
\text { Iowa State } & \$ 9.2 \mathrm{M}\end{array}$ \\
\hline Kansas & \$31.5 Million & $\begin{array}{l}\text { NIH \$11.6 Million } \\
\text { NSF \$ } 3.7 \text { Million } \\
\text { Other \$ } 22.5 \text { Million }\end{array}$ & $\begin{array}{ll}\text { U. of Kansas } & \$ 22.3 \mathrm{M} \\
\text { Kansas State } & \$ 5.5 \mathrm{M} \\
\text { WSU } & \$ 3.7 \mathrm{M}\end{array}$ \\
\hline Missouri & \$20.0 Million & $\begin{array}{l}\text { NIH } \$ 9.2 \text { Million } \\
\text { NSF \$ } 3.7 \text { Million } \\
\text { Other \$ } 6.6 \text { Million }\end{array}$ & $\begin{array}{l}\text { U. of Missouri } \$ 8.9 \mathrm{M} \\
\text { Washington U. } \$ 5.4 \mathrm{M} \\
\text { UM St. Louis \$ } 3.3 \mathrm{M}\end{array}$ \\
\hline Nebraska & \$16.8 Million & $\begin{array}{l}\text { NIH } \$ 5.1 \text { Million } \\
\text { NSF \$ } 2.2 \text { Million } \\
\text { Other \$ } 8.5 \text { Million }\end{array}$ & $\$ 15.8 \mathrm{M}$ \\
\hline
\end{tabular}

Table 1: SBSR funding by state, agency, and top universities in the region.

Table 1 provides a breakdown of fed- This is important because funding for traerally supported SBSR by State in Iowa, Kansas, Missouri, and Nebraska (Consortium of Social Science Associations, State Fact Sheets, n.d.). As shown in Table 1, each of the major universities in these four states have well-funded SBSR programs, with diverse funding portfolios. ditional disciplinary SBSR is becoming increasingly more competitive due to an increasing pool of applicants and decreases in SBSR federal funding. The result, as we see across the funding landscape, is lower federal funding rates.

While it is true that overall research funding has declined in real dollars over

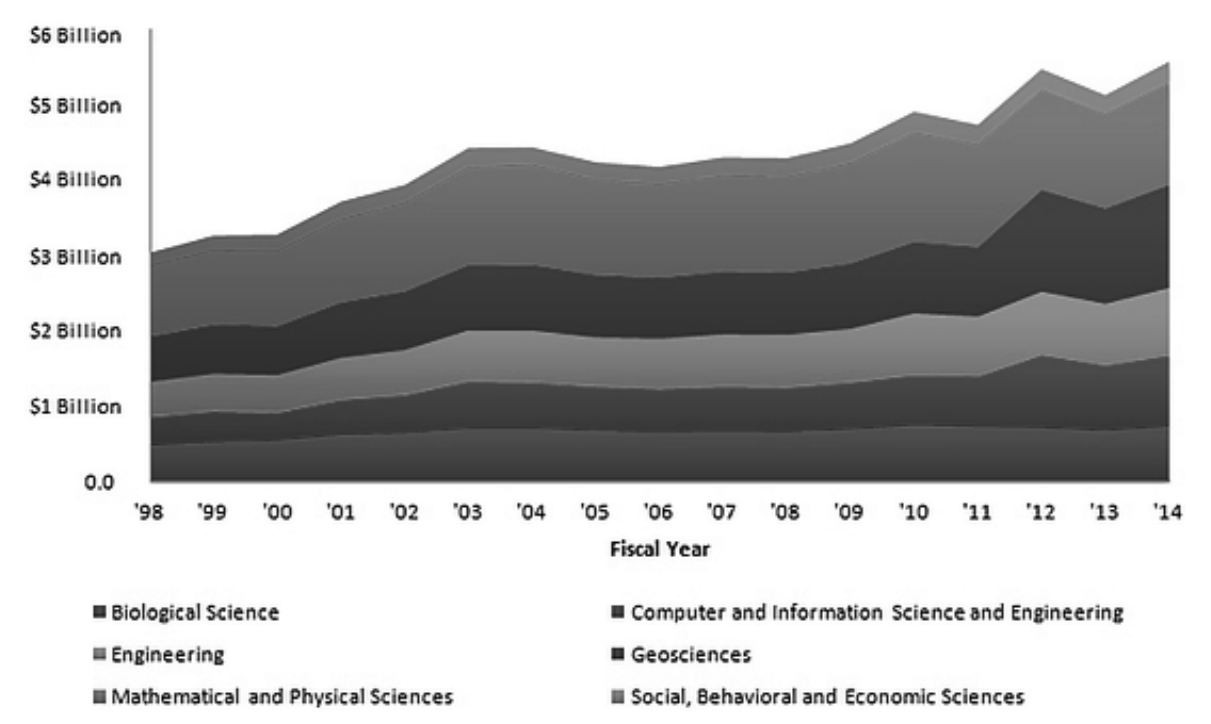

Table 2: NSF funding by directorate from FY 1998 through FY 2014 
the past decade, SBSR has been particularly hard hit. Consider for example the NSF research funding trends from 1998 through 2014, as shown in Table 2. NSF research funding (excluding educational, equipment, and operations) has increased from approximately \$3.5B in FY 1998 to approximately $\$ 6.1 \mathrm{~B}$ in FY 2014 (Todd, 2014). However, the research funding allocated to SBSR has remained a small proportion of the overall NSF research budget, declining from $4.9 \%$ in 1998 to $4.4 \%$ in 2014 .

Changes in federal funding from FY ample, the House Commerce, Justice, Science and Related Agencies (CJS) Appropriations Subcommittee FY16 report (2015) includes the following problematic language impacting social science funding:

"The Committee directs NSF to ensure that Mathematical and Physical Sciences; Computer and Information Sciences and Engineering; Engineering; and Biological Sciences comprise no less than 70 percent of the funding within Research and Related Activities."

\begin{tabular}{|llll|}
\hline Agency & $\begin{array}{l}2014 \\
\text { \$ Millions }\end{array}$ & $\begin{array}{l}\text { 2015 } \\
\text { \$ Millions }\end{array}$ & $\begin{array}{l}\text { Percent } \\
\text { Change }\end{array}$ \\
\hline NIH & 29,934 & 30,084 & +.5 \\
\hline NSF & 7,171 & 7,344 & +2.4 \\
\hline CDC & 5,807 & 5,968 & +2.8 \\
\hline DoE (IES) & 577 & 574 & -.5 \\
\hline ARHQ & 371 & 363 & -2.0 \\
\hline DoJ (BJS \& NIJ) & 85 & 77 & -9.5 \\
\hline
\end{tabular}

Table 3: Funding by agency for FY 2014 and FY 2015, with percent change noted.

2014 to FY 2015, shown in Table 3, have hit SBSR particularly hard. For example, DoE, ARHQ, and the Department of Justice (DoJ) are strong supporters of SBSR, and each experienced a budget cut. Funding directives for NIH and NSF include language for specific funding priorities that impact SBSR funding.

Fiscal Year 2016 looks to be even worse. At the time of this writing, Congress has not yet approved a FY16 budget (or even a Continuing Resolution), but early indicators indicate Congress is taking aim at SBSR funding in FY16. For ex-
In general, agencies and programs that support SBSR would fare quite poorly in the bill. Among the many challenging provisions, the bill seeks to (i) limit support for social science research at NSF, (ii) enable potentially deep cuts to the National Institute of Justice and $\mathrm{Bu}$ reau of Justice Statistics, and (iii) degrade the American Community Survey within the Census Bureau (Consortium of Social Science Associations, 2015).

The House report states:

"Social, Behavioral and Economic (SBE) Sciences-Long-standing congressional concerns persist about the merit 
of activities funded through NSF's SBE Directorate. In order to address these concerns, NSF must ensure that SBE awards are consistent with NSF's scientific quality standards and aligned to national interests. The Committee recognizes the intrinsic value in SBE sciences and the direct responsiveness of SBE activities to Committee priorities, including studies on the effects of youth exposure to media violence and the collection of data for STEM education indicators."

Table 4 provides a summary of the U.S. House and Senate versions of FY 2016 funding bills. Potential impacts on SBSR are not fully exposed by overall funding levels in NSF and NIH, but the
Institute of Educational Sciences (IES), within the DoE, is likely to experience a significant cut (up to $27 \%$ ). If the House has its way, ARHQ will be completely eliminated with its budget being zeroed out.

At this point, one might wonder why any university would consider investing additional resources in SBSR. To answer this question, one must remember why we conduct SBSR and what we hope to gain. Our long-term success in addressing major economic, health, energy, environmental and national security challenges depends on understanding not only their technological and scientific complexities, but also the broader social, political and economic issues that serve

\begin{tabular}{|lll|} 
Agency & House & Senate \\
\hline $\mathrm{NIH}$ & $+\$ 100 \mathrm{M}$ & $+\$ 2,000 \mathrm{M}(+\$ 2 \mathrm{~B})$ \\
\hline $\mathrm{NSF}$ & Small increase & Slightly higher increase \\
\hline CDC & Small increase & Small increase \\
\hline DoE $(\mathrm{IES})$ & $-\$ 155 \mathrm{M}(-27 \%)$ & Small decrease \\
\hline ARHQ & $-\$ 363 \mathrm{M}(-100 \%)$ & $-\$ 127 \mathrm{M}(-35 \%)$ \\
\hline DoJ (BJS \& NIJ) & Not Available & Not Available \\
\hline
\end{tabular}

Table 4: Proposed congressional changes in funding by agency for FY 2016.

impact becomes more visible when one starts to read the details of the bill. For example, House language on funding does not specify budgets for each directorate, but it includes language mandating the percentage of funding for certain classes of research, and specifies targeted initiatives, that would result in reductions in funding for the Social, Behavioral and Economic Sciences Directorate (SBE). The situation is much more dire for the smaller agencies that focus on SBSR. The as the context for addressing these matters. For example, we all know we should eat balanced diets and exercise regularly, yet few of us do either. The answer to many of society's problems are known, the challenge is figuring out how to change behaviors to adopt solutions to the problems ailing our society.

At UNL, we believe it is best to invest now, when the 'market is down', rather than wait until the 'market is hot'. But we must make wise investments, so that we 
are prepared for future funding opportunities and challenges. We need to move from thinking of research defined by disciplinary boundaries and expertise to research foci that require the collaboration of researchers across disciplines, bringing diverse theoretical and methodological approaches to address a common research challenge.

As societal problems have become more complex, it has become widely accepted that we need new ways to address today's research challenges. Thus, the past decade has been marked by a steady transition from funding traditional disciplinary-based research to increased funding of interdisciplinary research projects. Before addressing the impacts of that transition, it is important to define the term.

"Interdisciplinary research is a mode of research by teams or individuals that integrates information, data, techniques, tools, perspectives, concepts, and/or theories from two or more disciplines or bodies of specialized knowledge to advance fundamental understanding or to solve problems whose solutions are beyond the scope of a single discipline or area of research practice." (Committee on Facilitating Interdisciplinary Research, Committee on Science, Engineering, and Public Policy, 2004).

Aboelela et al. define interdisciplinary research as being

"based upon a conceptual model that links or integrates theoretical frameworks from those disciplines, uses study design and methodology that is not limited to any one field, and requires the use of perspectives and skills of the involved disciplines throughout multiple phases of the research process." (Aboelela, Larson, Bakken, et al., 2007)

National funding agencies, such as NSF and NIH, have greatly increased the portions of their budgets allocated toward creating interdisciplinary research programs. For example, the NSF Rebuilding the Mosaic initiative promotes interdisciplinary, data intensive, and collaborative research with four crosscutting themes:

- Population Change: Fundamental to Unpacking Key Research Problems;

- Disparities: Sources and Consequences;

- Understanding: Brain, Behavior, Communication, Learning and Language; and

- Technology: New Media and Social Networks.

The Interdisciplinary Behavioral and Social Science Research (IBSS) competition promotes the conduct of interdisciplinary research by teams of investigators. Emphasis is placed on support for research that involves researchers from multiple SBE disciplinary fields and that integrates scientific theoretical approaches and methodologies from multiple SBE disciplinary fields.

Importantly, interdisciplinary funding opportunities are not limited to SBSR directorates.

- Secure and Trustworthy Cyberspace (SaTC): The National Science and Technology Council (NSTC) with the cooperation of NSF issued a broad, coordinated Federal strategic plan for cybersecurity research that "requires a dedicated approach to research, development, and education that leverages the disciplines of mathematics 
and statistics, the social sciences, and engineering together with the computing, communications and information sciences". (NSF Program Solicitation NSF 15-575, 2015).

- Critical Techniques and Technologies for Advancing Foundations and Applications of Big Data Science and Engineering (BIGDATA): "The BIG$D A T A$ program seeks novel approaches in computer science, statistics, computational science, and mathematics, along with innovative applications in domain science, including social and behavioral sciences, geosciences, education, biology, the physical sciences, and engineering that lead towards the further development of the interdisciplinary field of data science." (NSF Program Solicitation 15-544, 2015).

- The NIH has taken a bolder approach to interdisciplinary research (IR):

"Health research traditionally has been organized much like a series of cottage industries, lumping researchers into specialty areas, where their efforts remain disconnected from the greater whole by artificial barriers constructed by technical and language differences between different disciplines and departmentally-based specialties. But, as science has advanced over the past decade, two fundamental themes are apparent: the study of human biology and behavior is a wonderfully dynamic process, and the traditional divisions within health research may in some instances impede the pace of scientific discovery."
"The broad goal for the IR program therefore, was to change academic research culture, both in the extramural research community and in the extramural program at the NIH, such that interdisciplinary approaches are facilitated. The Interdisciplinary Research Program included initiatives to dissolve academic department boundaries within academic institutions and increase cooperation between institutions, train scientists to cultivate interdisciplinary efforts, and build bridges between the biological sciences and the behavioral and social sciences. Collectively, these efforts were intended to change academic research culture so that interdisciplinary approaches and team science are a normal mode of conducting research and scientists who pursue these approaches are adequately recognized and rewarded." (NIH Office of Strategic Coordination - The Common Fund, n.d.).

- The NIH Office of Behavioral and Social Sciences Research seeks to address the "complexity inherent in behavioral and social phenomena, referred to as systems science methodologies" and "promote interdisciplinary collaboration among health researchers and experts in computational approaches to further the development of modeling- and simulation-based systems science methodologies and their application." (NIH Funding Opportunity Announcement PAR-15047, 2014)

Similar language is found in their health disparities research programs: 
"Research on the causes and solutions to health and disabilities disparities in the U.S. population. Health disparities between, on the one hand, racial/ethnic populations, lower socioeconomic classes, and rural residents and, on the other hand, the overall U.S. population are major public health concerns." "Applications that utilize an interdisciplinary approach, investigate multiple levels of analysis and/or employ innovative methods such as systems science or community-based participatory research are particularly encouraged." (NIH U.S. National Library of Medicine, n.d.)

Before the federal funding agencies started creating these 'new' programs, UNL was investing heavily in interdisciplinary SBSR. In 2004, the Nebraska Center for Research on Children, Youth, Families and Schools (CYFS) was established. The mission of the CYFS is "to advance the conduct of high-quality interdisciplinary research to promote the intellectual, behavioral, and social-emotional development and functioning of individuals across educational, familial and community contexts" (Nebraska Center for Research on Children, Youth, Families and Schools, n.d.). Investments in interdisciplinary SBSR faculty, centers, and other activities continues to this date, with the most recent high profile initiative being the Substance Abuse and Violence Initiative (SAVI), which began in 2010. SAVI brings together an interdisciplinary team to address the complex intersection between substance abuse and violence (Substance Abuse and Violence Initiative, n.d.).
In the Spring of 2012, UNL began to explore new methods, beyond interdisciplinary teams, to solving complex SBSR challenges by forming and funding transdisciplinary teams. Transdisciplinary Research is defined as "research efforts conducted by investigators from different disciplines working jointly to create new conceptual, theoretical, methodological, and translational innovations that integrate and move beyond discipline-specific approaches to address a common problem" (Harvard Transdisciplinary Research in Energetics and Cancer Center, n.d.).

Based upon an assessment of where we had potential to expand collaborative research, our first step was to launch the Minority Health Disparities Initiative (MHDI) a transdisciplinary initiative with a focus on research, outreach, and training on health disparities (UNL Minority Health Disparities Initiative, n.d.). The investigators associated with this initiative have been successful in obtaining significant funding from NIH, with multiple \$3M+ R01 awards ranging from research on HIV Injection Risk Networks in Rural Puerto Rico to a Randomized Control Trial of a Culturally-Based Substance Abuse Intervention for Aboriginal Youth. MHDI also received funding from NSF for a summer REU program that aims to train the next generation of scientists in minority health disparities and social network analysis.

Shortly after that, UNL began the formation of the Center for Brain, Biology and Behavior (CB3). CB3 is a transdisciplinary center that brings together distinguished UNL faculty in the social, behav- 
ioral and biological sciences and engineering (UNL Center for Brain, Biology and Behavior, n.d.). It also represents a unique partnership between academics and athletics at the UNL, with CB3 moving into a new expansion of Memorial Stadium in early 2014. This center's multidisciplinary environment enables diverse studies to expand our understanding of brain function and its effects on human behavior. An early and significant focus is on minor traumatic brain injury, which many athletes sustain in the form of concussions. More broadly, the center offices and labs house researchers who are at the forefront in the study of genetics, neuroscience, physiology, cognition and other areas of brain science.

The SBSR Initiative at UNL began in June of 2012 when the UNL Vice Chancellor for Research, Prem Paul, charged a faculty task force with answering several interrelated goals (UNL Social and Behavioral Sciences Research Initiative Task Force Report, 2014):

- enhance research excellence in the social and behavioral sciences at UNL,

- enhance competitiveness of UNL faculty in the social and behavioral sciences for extramural funding,

- identify gaps in faculty expertise that must be addressed to build successful teams of social and behavioral science researchers, and

- identify infrastructure or other needs to assist social and behavioral sciences faculty to be more productive and competitive for extramural funding.

A significant first accomplishment associated with the UNL SBSR Initiative was to enhance infrastructure by winning a \$300,000 NSF grant to launch the Central Plains Research Data Center (RDC). The RDC is established in collaboration with the U.S. Census Bureau's Center for Economic Studies and includes partnership with the University of Nebraska Medical Center, Iowa State University, the University of Iowa and the University of South Dakota (UNL Central Plains Research Data Center, 2014). The center will be joining a network of 18 such centers in the U.S. that are jointly funded by the Census Bureau and the National Science Foundation. Slated to open in fall 2015, this Federal Statistical Research Data Center provides researchers in the social, behavioral, health and life sciences across the region a secure environment that allows access to restricted-use data from the Census Bureau, National Center for Health Statistics, Bureau of Labor Statistics, National Center for Education Statistics, Department of Transportation, Department of Housing and Urban Development and other federal sources. The center will provide access to a wealth of federal and regional data available on campus producing unique opportunities for enhancing social and behavioral research.

Building upon the recommendations outlined in the SBSR Initiative task force report, which was delivered in the spring of 2014, the UNL Office of Research and Economic Development established the Social and Behavioral Sciences Research Consortium (SBSRC) [UNL Social and Behavioral Sciences Research Consortium, n.d.]. The task force report highlighted areas of SBSR strength on cam- 
pus, but noted the need to enhance connections and collaborations. This was a primary motivation in the branding of this effort as a "consortium", highlighting a primary goal to bring social and behavioral scientists together to address common research challenges regardless of department, college, or even campus affiliation.

SBSRC's mission is to facilitate the growth of social and behavioral research through coordinated activities that include:

- building a referral network for existing resources,

- enhancing research capacity,

- $\quad$ providing seed and voucher support,

- identifying and building research collaborations, and

- providing mentoring for new investigators.

An initial project in the center will be to use network science analyses to assess the type and extent of current interdisciplinary collaborations. The SBSRC is mapping all grant activity over the past 4 years that includes SBSR faculty. This analysis will be complemented by a second science network mapping of areas of research specialization and publications for the SBSR faculty. Combined, these analyses provide a baseline assessment of current interdisciplinary and transdisciplinary collaborations as well as identify opportunities for future collaborations. This work will also assist us in identifying areas where strategic faculty hires could greatly enhance our ability to build interdisciplinary teams positioned to respond to funding opportunities.
It was clear from the SBSR Initiative task force report that another need was to create a central assessment and referral mechanism. The report made it clear that more effort needed to be invested in informing faculty about existing SBSR resources. Again highlighting the 'consortium' element of the SBSRC, a core activity in the initial year is to create a comprehensive inventory of UNL SBSR resources and expertise. These data will then be used to build a referral network that will facilitate and support team research. SBSRC will identify new opportunities for collaboration, provide seed funding, coordinate external funding opportunities and provide mentoring for new faculty. In this effort, SBSRC will work closely with existing initiatives and centers, including seed funding in the form of vouchers for faculty to work with existing research support units.

The SBSR Initiative task force report also identified areas of research infrastructure that needed to be supported and/or enhanced to facilitate the growth of new social and behavioral collaborations. Accordingly, a first activity of the SBSRC was to submit a University of Nebraska Research Initiative grant for enhanced core facility support for social and behavioral research. This grant was funded at the start of the fiscal year and the SBSRC is in process of developing additional research infrastructure supporting social and behavioral research.

It is important to note that we have started this strategic investment with a strong base of social and behavioral scientists who were recruited to UNL through collaborative efforts of academic departments, colleges, and the office of 
research. In addition, there are existing campus research centers with major social and behavioral research foci, including the Nebraska Center for Research on Children, Youth, Families and Schools, the Center for Children Families and the Law, and the Public Policy Center. The new investments in MHDI, CB3 and the RDC enhance this base of SBSR initiatives and centers. The referral, coordination, and supplemental services provided through SBSRC add the final element in the plan to increase SBSR funding in this competitive research environment.

In summary, is now the time to invest in social and behavioral science research? Obviously at UNL the answer is yes! We believe SBSR will continue to play significant roles in addressing our societies' biggest challenges. The growth opportunities, however, are in interdisciplinary and transdisciplinary team science approaches, rather than traditional single-investigator research projects. We are confident that our approach will position UNL to be a leading institution in transdisciplinary social and behavioral science research.

\section{References}

Aboelela SW, Larson E, Bakken S, et al. (2004) "Defining interdisciplinary research: conclusions from a critical review of the literature." Health Serv Res. 2007; 42:329-346.

Committee on Facilitating Interdisciplinary Research, Committee on Science, Engineering, and Public Policy (2004). Facilitating interdisciplinary research. National Academies. Washington: National Academy Press.

Consortium of Social Science Associations. (2015) “COSSA Analysis of the FY 2016 House Commerce, Justice, Science and
Related Agencies Appropriations Act." (accessed August 17, 2015):

http://www.cossa.org/wp-content/uploads/2015/05/FY-2016-House-CJS-Analysis-19May2015.pdf

Consortium of Social Science Associations.

"State Fact Sheets", (accessed August 17, 2015): http://www.cossa.org/resources/state-fact-sheets/

Harvard Transdisciplinary Research in Energetics and Cancer Center. (n.d.). "Definitions" (accessed August 17, 2015): http://www.hsph.harvard.edu/trec/aboutus/definitions

House Commerce, Justice, Science and Related Agencies (CJS) Appropriations Subcommittee FY16 Report. (2015). (accessed August 17, 2015): http://appropriations.house.gov/uploadedfiles/hrpt-114hr-fy2016-cjs.pdf

NIH Funding Opportunity Announcement PAR-15-047. (2014). “Systems Science and Health in the Behavioral and Social Sciences (R21)" (accessed August 17, 2015): http://grants.nih.gov/grants/guide/pafiles/PAR-15-047.html

NIH Office of Strategic Coordination - The Common Fund (n.d.). "Interdisciplinary Research Overview" (accessed August 17, 2015): https://commonfund.nih.gov/Interdisciplinary/overview

NIH U.S. National Library of Medicine. (n.d.). "Behavioral and Social Science Research on Understanding and Reducing Health Disparities Grants" (accessed August 17, 2015): http://www.nlm.nih.gov/ep/healthdisp.ht $\mathrm{ml}$

NSF Program Solicitation 15-544. (2015). "NSF Critical Techniques and Technologies for Advancing Foundations and Applications of Big Data Science and Engineering (BIGDATA)." (accessed August 17, 2015): https://www.nsf.gov/mobile/funding/pgm_summ.jsp?pims_id=504767 
NSF Program Solicitation 15-575. (2015).

“NSF Secure and Trustworthy Cyberspace (SaTC)". (accessed August 17, 2015): https://www.nsf.gov/funding/pgm_summ.jsp?pims_id=504709

Todd, Michael. (2014). “How Much NSF Funding Goes to Social Science?" Social Science Space. (accessed August 17, 2015): http://www.socialsciencespace.com/2014/03/how-much-nsf-funding-goes-to-social-science

UNL Center for Brain, Biology and Behavior. (n.d.). (accessed August 17, 2015): http://cb3.unl.edu

UNL Central Plains Research Data Center. (2014) "Research Data Center expands possibilities" (August 17, 2015):

http://research.unl.edu/researchnews/september2014/rdc-expands-research-possibilities/
UNL Minority Health Disparities Initiative. (n.d.). (accessed August 17, 2015): http://mhdi.unl.edu

UNL Nebraska Center for Research on Children, Youth, Families and Schools. (n.d.). (accessed August 17, 2015): http://cyfs.unl.edu/cyfs/about

UNL Social and Behavioral Sciences Research Consortium. (n.d.). (August 17, 2015): http://sbsrc.unl.edu

UNL Social and Behavioral Sciences Research Initiative Task Force Report. (2014). 0(accessed August 17, 2015): http://research.unl.edu/facultyretreat14/wp-content/uploads/sites/19/2014/04/SBSRI-Task-ForceReport-Final.pdf

UNL Substance Abuse and Violence Initiative. (n.d.). (accessed August 17, 2015): http://psychology.unl.edu/savi/about-savi 